\title{
Maternal Nutrition in Twin Gestations: Weight Gain, Cravings and Aversions, and Sources of Nutrition Advice
}

\section{B. Luke' ${ }^{1}$ L. Keith ${ }^{2,3}$, D. Keith ${ }^{3}$}

${ }^{1}$ Department of Obstetrics and Gynecology, University of Michigan Medical School, Ann Arbor, Michigan; ' Department of Obstetrics and Gynecology, Northwestern University and the ${ }^{3}$ Center for the Study of Multiple Births, Chicago, Illinois

\begin{abstract}
Background: Maternal nutrition has a strong influence on singleton and twin birthweight. This study evaluated the association between twin birthweight and maternal pregravid body mass index (BMI), weight gain, and cravings and aversions. Information was also obtained regarding sources of nutrition advice and advised versus actual weight gain.
\end{abstract}

Methods: This study is based on data from interviews with 928 mothers of twins. Univariate analysis included comparisons by source of nutritional advice, birthweight categories, and categories of cravings and aversions. Multiple logistic regression was used to formulate models for mean twin birthweights $>1,500 \mathrm{~g}$ and $>2,500 \mathrm{~g}$.

Results: Mothers who received their nutrition advice from a registered dietitian had the highest weight gains and the lowest proportion of birthweights $<1,500 \mathrm{~g}$. For mean twin birthweight $>2,500 \mathrm{~g}$, the final model included prematurity, pregravid BMI, and weight gain; for birthweights $>1,500 \mathrm{~g}$, the model additionally included maternal age and aversions.

Conclusions: Maternal pregravid BMI and gestational weight gain were shown to be important factors influencing twin birthweight. Nutrition advice, particularly from a registered dietitian, may be vital in assuring adequate weight gain, and therefore better birthweights, for these high-risk pregnancies.

Key words: Maternal weight gain, Nutrition advice, Twin birthweight

\section{INTRODUCTION}

During the past twenty years the incidence of multiple births has risen dramatically, due to the use of assisted reproductive techniques, as well as a trend towards delaying childbirth [23]. In 1995, the most recent year for which vital statistics are available in the US, 
there were 101,709 liveborn infants of multiple births, including 96,736 infants of twin births [37]. Although infants of twin gestations represent only about $2 \%$ of all live births in the United States, compared to singletons they are five times more likely to be born premature ( $<37$ weeks' gestation), 9.5 times more likely to be very low birthweight $(<1,500 \mathrm{~g})$, and 8.5 times more likely to be low birthweight $(<2,500 \mathrm{~g})$ [19]. At every gestational age, twins with better birthweights have lower morbidity and mortality than their smaller counterparts $[21,24]$. There is a growing body of clinical research indicating that nutrition may play an important role in twin birthweight, particularly maternal pregravid weight and gestational weight gain $[5,20,22,25,26,30]$.

As part of a multi-year survey of maternal nutrition and the childhood growth of twins at the annual Twins Days Festival in Twinsburg, Ohio, mothers of twins were interviewed regarding a variety of maternal nutrition issues, including advised and actual weight gain, cravings and aversions, prematurity, and the birthweights of their twins. The purpose of this portion of the survey was to evaluate the association between twin birthweight and maternal pregravid weight, weight gain, and gestational cravings and aversions. In addition, the survey sought to collect information regarding actual versus advised gestational weight gain, and sources of nutrition advice. This study was approved by the Human Investigation Committee at Johns Hopkins University, the institution of the principal investigator at the initiation of the study.

\section{MATERIALS AND METHODS}

The Twins Days Festival is held annually during the first weekend of August in Twinsburg, Ohio (about 30 miles south of Clevelend), and includes children and adults of multiple gestations and their families. The nutrition component of this study was conducted during 1989, 1990, 1991, and 1993, and included interviews with 928 mothers of twins and information on their 1,856 children. The interview included questions on maternal age and pregravid weight before the twin pregnancy, height, education, advised and actual gestational weight gain, sources of nutrition advice, cravings and aversions, birthweights of the twins, and whether the pregnancy was premature. Based on height and pregravid weight, body mass index (BMI) was calculated and modelled as continuous and categorical variables (underweight, normal weight, overweight, or obese), according to the most recent recommendations from the National Academy of Sciences [13]. Actual weight gain was modelled as continuous and categorical variables $(<20 \mathrm{lbs}, 20-29 \mathrm{lbs}$, $30-39 \mathrm{lbs}$, and $\geq 40 \mathrm{lbs}$ ). The birthweight of each twin pair was averaged and then modelled as continuous, categorical $(<1,500 \mathrm{~g}, 1,500-2,000 \mathrm{~g}, 2,001-2,500 \mathrm{~g}$, and $>2,500 \mathrm{~g})$, and dichotomous $(<1,500 \mathrm{~g}$ vs $\geq 1,500 \mathrm{~g}$ and $<2,500 \mathrm{~g}$ vs $\geq 2,500 \mathrm{~g})$ variables. Gestation was modelled as a binary variable ( $<37$ weeks or $\geq 37$ weeks). Women were categorised by their cravings and aversions as having cravings only, cravings and aversions, no cravings or aversions, or aversions only. The data was first described for the entire sample, then by source of nutrition advice, birthweight categories, and cravings versus aversions. The data was analyzed using chi-square for categorical variables, Student's t test between two groups of continuous variables, and analysis of variance between more than two groups of continuous variables, with significance at $\mathrm{p}<.05$, two-tailed. The Bonferroni correction was used when comparing proportions of the eight types of cravings for 
women with cravings only versus women with both cravings and aversions; the resulting $\mathrm{p}$ value considered significant was $.05 / 8=.006$. The Bonferroni correction was also used when comparing proportions of the nine types of aversions for women with cravings and aversions versus women with aversions only; the resulting $\mathrm{p}$ value considered significant was $.05 / 9=.0055$. Multiple logistic regression analysis was then conducted to formulate models for mean twin birthweight $>1,500 \mathrm{~g}$ and $>2,500 \mathrm{~g}$.

\section{RESULTS}

A total of 928 mothers were interviewed during the four-year period, and data was collected on them and their 1,856 twin children. About half of the births were premature, with a mean birthweight of about $2,500 \mathrm{~g}$. About $5 \%$ of infants weighed less than $1,500 \mathrm{~g}$ (compared to about $9 \%$ of twins nationally), and about $50 \%$ weighed more than $2,500 \mathrm{~g}$ (comparable to national figures). About $25 \%$ of mothers were underweight before conception, $55 \%$ were normal weight, and about $20 \%$ were either overweight or obese. Advised weight gain averaged about 31 pounds and actual weight gain about 41 pounds. Nearly $60 \%$ of mothers received nutrition advice from their physicians, $12 \%$ from a registered dietitian, about $21 \%$ from television or books, $5 \%$ from other sources, and about $3 \%$ received no advice. About $41 \%$ of mothers experienced cravings during their twin pregnancy, including pastries $(32 \%)$, ice cream $(30 \%)$, fruits $(30 \%)$, chocolate $(25 \%)$, salty foods $(20 \%)$, and spicy foods $(20 \%)$. About $35 \%$ of mothers experienced aversions during pregnancy, including cigarettes $(37 \%)$, fried foods $(31 \%)$, coffee $(29 \%)$, red meat $(18 \%)$, alcohol (15\%), tomatoes $(10 \%)$, carbonated beverages $(8 \%)$, and poultry $(6 \%)$.

A comparison of maternal characteristics and birth outcomes by sources of nutrition advice is given in Table 1 . Women who had not received any nutrition advice were least likely to have attended college $(69 \%)$, were most likely to be either overweight or obese $(35 \%)$ and to have gained $<20$ pounds $(19 \%)$, had the highest proportion of aversions $(54 \%)$, and the highest proportion of very low birthweight infants $(12 \%)$. In contrast, women who received their nutrition advice from a registered dietitian had the highest advised and actual weight gains ( 36 pounds and 46 pounds, respectively), were most likely to have gained $\geq 40$ pounds $(60 \%)$, and had the lowest proportion of very low birthweight infants $(2 \%)$.

A comparison of characteristics across birthweight categories is given in Table 2. From birthweights of $<1,500 \mathrm{~g}$ to $>2,500 \mathrm{~g}$ there was a significant decline in the proportion of prematurity (from $100 \%$ to $34 \%$ ), reported aversions (53\% to $32 \%$ ), and a significant increase in the proportion of mothers with some college or who were college graduates $(67 \%$ to $82 \%)$ and who were overweight or obese $(13 \%$ to $23 \%)$, mean pregravid BMI (from 21.5 to 23.4 ), and actual weight gain (from 35.7 pounds to 44.8 pounds).

A comparison of characteristics by categories of cravings and aversions is given in Table 3. Mothers reporting both cravings and aversions had the highest proportion of prematurity $(65 \%)$ and the lowest mean birthweight $(2,394 \mathrm{~g} \pm 630)$, while mothers reporting neither cravings nor aversions had the lowest proportion of prematurity $(44 \%)$ and the highest mean birthweight $(2,517 \mathrm{~g} \pm 546)$. Mothers who experienced cravings only had the lowest proportion of very low birthweight infants $(2 \%)$, whereas mothers with both cravings and aversions had the highest proportion $(9 \%)$. 
Table 1 - Comparison of characteristics by source of nutritional advice

\begin{tabular}{|c|c|c|c|c|c|}
\hline $\begin{array}{l}\text { Characteristic } \\
\text { (N) }\end{array}$ & $\begin{array}{c}\text { Physician } \\
(550)\end{array}$ & $\begin{array}{l}\text { Registered } \\
\text { Dietitian } \\
\text { (113) }\end{array}$ & $\begin{array}{c}\text { Books or } \\
\text { Television } \\
\text { (192) }\end{array}$ & $\begin{array}{l}\text { Other } \\
(47)\end{array}$ & $\begin{array}{l}\text { None } \\
\text { (26) }\end{array}$ \\
\hline Premature $(\%)$ & $51 \%$ & $56 \%$ & $56 \%$ & $51 \%$ & $58 \%$ \\
\hline Education (years) & $13.9 \pm 2.1$ & $14.2 \pm 2.0$ & $15.0 \pm 2.4$ & $15.3 \pm 3.1$ & $13.7 \pm 1.7$ \\
\hline High School graduate (\%) & $24 \%$ & $20 \%$ & $12 \%$ & $19 \%$ & $31 \%$ \\
\hline$>$ High School $(\%)$ & $76 \%$ & $80 \%$ & $88 \%$ & $81 \%$ & $69 \%$ \\
\hline Pregravid BMI & $22.8 \pm 4.9$ & $23.2 \pm 4.6$ & $22.9 \pm 5.0$ & $24.3 \pm 5.5$ & $23.4 \pm 8.6$ \\
\hline Underweight (BMI < 19.8) & $26 \%$ & $29 \%$ & $20 \%$ & $21 \%$ & $23 \%$ \\
\hline Normal Weight (BMI 19.8-26.0) & $55 \%$ & $41 \%$ & $66 \%$ & $49 \%$ & $42 \%$ \\
\hline Overweight (BMI 26.1-29.0) & $8 \%$ & $20 \%$ & $7 \%$ & $19 \%$ & $19 \%$ \\
\hline Obese $(\mathrm{BMI}>29.0)$ & $11 \%$ & $10 \%$ & $7 \%$ & $11 \%$ & $16 \%$ \\
\hline \multicolumn{6}{|l|}{ Weight Gain (pounds) } \\
\hline Advised & $30.1 \pm 11.2$ & $36.0 \pm 12.7$ & $34.2 \pm 12.8$ & $27.2 \pm 11.2$ & - \\
\hline Actual & $40.2 \pm 16.2$ & $46.3 \pm 16.1$ & $43.1 \pm 17.2$ & $39.2 \pm 12.1$ & $37.1 \pm 24.5$ \\
\hline$\%<20$ pounds & $9 \%$ & $0 \%$ & $8 \%$ & $4 \%$ & $19 \%$ \\
\hline$\% 20-29$ pounds & $17 \%$ & $14 \%$ & $13 \%$ & $13 \%$ & $35 \%$ \\
\hline$\% 30-39$ pounds & $24 \%$ & $26 \%$ & $24 \%$ & $32 \%$ & $15 \%$ \\
\hline$\% \geq 40$ pounds & $50 \%$ & $60 \%$ & $55 \%$ & $51 \%$ & $31 \%$ \\
\hline Cravings (\%) & $42 \%$ & $45 \%$ & $35 \%$ & $38 \%$ & $42 \%$ \\
\hline Aversions (\%) & $31 \%$ & $43 \%$ & $40 \%$ & $36 \%$ & $54 \%$ \\
\hline Twin Pair Mean Birthweight ( $\mathrm{g}$ ) & $2488 \pm 566$ & $2431 \pm 499$ & $2490 \pm 539$ & $2352 \pm 557$ & $2468 \pm 725$ \\
\hline$\%<1,500 \mathrm{~g}$ & $5 \%$ & $2 \%$ & $6 \%$ & $3 \%$ & $12 \%$ \\
\hline$\% 1,500-2,000 \mathrm{~g}$ & $13 \%$ & $19 \%$ & $11 \%$ & $28 \%$ & $19 \%$ \\
\hline$\% 2,001-2,500 \mathrm{~g}$ & $33 \%$ & $29 \%$ & $31 \%$ & $26 \%$ & $23 \%$ \\
\hline$\%>2,500 \mathrm{~g}$ & $49 \%$ & $50 \%$ & $52 \%$ & $43 \%$ & $46 \%$ \\
\hline
\end{tabular}

Values are given as means \pm standard deviations for continuous variables and percent frequency for categorical variables. NS is not significant, $\mathrm{p}$ value $>.05$, two-tailed

Two multiple logistic regression models were formulated using stepwise regression: one for mean twin birthweight $>1,500 \mathrm{~g}$ and another for mean twin birthweight $>2,500 \mathrm{~g}$. The adjusted odds ratios and $95 \%$ confidence intervals $(\mathrm{Cl})$ for the five factors in the final model for mean twin birthweight $>1,500 \mathrm{~g}$ were prematurity $(0.05$, 95\% CI, 0.007-0.39), maternal age (1.11, 95\% CI, 1.04-1.20), pregravid BMI (1.11, $95 \% \mathrm{CI}, 1.01-1.22)$, weight gain $(1.05,95 \% \mathrm{CI}, 1.02-1.08)$, and aversions $(0.31,95 \%$ $\mathrm{CI}, 0.08-0.13$ ); the model chi-square was $53.91, \mathrm{p}<.00001$. For mean twin birthweight $>2,500 \mathrm{~g}$, the adjusted odds ratios and $95 \% \mathrm{Cls}$ for the three factors in the final model 
Table 2 - Comparison of characteristics by birthweight categories

\begin{tabular}{|c|c|c|c|c|c|}
\hline $\begin{array}{l}\text { Characteristic } \\
\text { (N) }\end{array}$ & $\begin{array}{c}<1,500 \mathrm{~g} \\
\quad(48)\end{array}$ & $\begin{array}{c}1,500- \\
2,000 \mathrm{~g} \\
(131)\end{array}$ & $\begin{array}{c}2,001- \\
2,500 \mathrm{~g} \\
(293)\end{array}$ & $\begin{array}{c}>2,500 \mathrm{~g} \\
(456)\end{array}$ & p Value * \\
\hline Premature (\%) & $100 \%$ & $84 \%$ & $61 \%$ & $34 \%$ & $<.0001$ \\
\hline Education(years) & $13.5 \pm 1.8$ & $13.9 \pm 2.0$ & $14.3 \pm 2.2$ & $14.4+2.3$ & .05 \\
\hline High School graduate $(\%)$ & $33 \%$ & $27 \%$ & $20 \%$ & $18 \%$ & \\
\hline > High School $(\%)$ & $67 \%$ & $73 \%$ & $80 \%$ & $82 \%$ & .01 \\
\hline Pregravid BMI & $21.5 \pm 4.4$ & $22.5 \pm 4.2$ & $22.7 \pm 4.9$ & $23.4 \pm 5.4$ & .03 \\
\hline Underweight (BMI<19.8) & $27 \%$ & $27 \%$ & $27 \%$ & $22 \%$ & \\
\hline Normal Weight (BMI 19.8-26.0) & $60 \%$ & $56 \%$ & $54 \%$ & $55 \%$ & \\
\hline Overweight (BMI 26.1-29.0) & $13 \%$ & $9 \%$ & $8 \%$ & $12 \%$ & \\
\hline Obese $($ BMI $>29.0)$ & $0 \%$ & $8 \%$ & $11 \%$ & $11 \%$ & NS \\
\hline \multicolumn{6}{|l|}{ Weight Gain (pounds) } \\
\hline Advised & $29.0 \pm 10.2$ & $34.1 \pm 14.9$ & $30.1 \pm 10.5$ & $31.6 \pm 12.1-$ & NS \\
\hline Actual & $35.7 \pm 13.3$ & $36.9 \pm 13.1$ & $38.6 \pm 16.2$ & $44.8 \pm 17.3$ & $<.0001$ \\
\hline$\%<20$ pounds & $11 \%$ & $8 \%$ & $9 \%$ & $7 \%$ & \\
\hline$\%$ 20-29 pounds & $13 \%$ & $21 \%$ & $24 \%$ & $10 \%$ & \\
\hline$\%$ 30-39 pounds & $47 \%$ & $34 \%$ & $31 \%$ & $29 \%$ & \\
\hline$\% \geq 40$ pounds & $29 \%$ & $37 \%$ & $36 \%$ & $54 \%$ & $<.0001$ \\
\hline Cravings (\%) & $49 \%$ & $52 \%$ & $41 \%$ & $37 \%$ & .01 \\
\hline Aversions (\%) & $53 \%$ & $41 \%$ & $34 \%$ & $32 \%$ & .02 \\
\hline
\end{tabular}

Values are given as means \pm standard deviations for continuous variables and percent frequency for categorical variables. $\quad *$ NS is not significant, $\mathrm{p}>.05$, two-tailed

were prematurity $(0.37,95 \% \mathrm{Cl}, 0.25-0.53)$, pregravid $B M I(1.10,95 \% \mathrm{Cl}, 1.06-1.15)$, and weight gain $(1.03,95 \% \mathrm{Cl}, 1.02-1.04)$; the model chi-square was $75.77, \mathrm{p}$ $<.00001$.

\section{DISCUSSION}

The results of this study confirm previous reports of the importance of maternal nutrition on birthweight. Numerous studies with singleton pregnancies have shown a strong association between birthweight and maternal pregravid weight and weight gain $[1,14,27$, 33, 38]. Although fewer studies have been conducted with twin pregnancies, both of these maternal factors have also been shown to be strongly associated with twin birthweight $[5,20,22,25,26,30]$. The new finding in this study, that twin birthweights $>1,500 \mathrm{~g}$ were significantly associated with a lack of pregnancy aversions, has not been previously reported. Cravings and aversion, as well as pica, have been reported in single- 
Table 3 - Comparison of characteristics by categories of cravings and aversions

\begin{tabular}{|c|c|c|c|c|c|}
\hline $\begin{array}{l}\text { Characteristic } \\
\text { (N) }\end{array}$ & $\begin{array}{c}\text { Cravings } \\
\text { Only } \\
(142)\end{array}$ & $\begin{array}{c}\text { Cravings \& } \\
\text { Aversions } \\
\quad(238)\end{array}$ & $\begin{array}{c}\text { No Cravings } \\
\text { or Aversions } \\
(460)\end{array}$ & $\begin{array}{l}\text { Aversions } \\
\text { Only } \\
(88)\end{array}$ & p Value* \\
\hline Premature (\%) & $59 \%$ & $65 \%$ & $44 \%$ & $59 \%$ & $<.0001$ \\
\hline Twin Pair Mean Birthweight (g) & $2465 \pm 511$ & $2394 \pm 630$ & $2517 \pm 546$ & $2481 \pm 451$ & .05 \\
\hline$\%<1,500 \mathrm{~g}$ & $2 \%$ & $9 \%$ & $4 \%$ & $4 \%$ & \\
\hline$\% 1,500-2,000 \mathrm{~g}$ & $15 \%$ & $19 \%$ & $12 \%$ & $8 \%$ & \\
\hline$\% 2,001-2,500 \mathrm{~g}$ & $37 \%$ & $28 \%$ & $31 \%$ & $37 \%$ & \\
\hline$\%>2,500 \mathrm{~g}$ & $46 \%$ & $44 \%$ & $53 \%$ & $51 \%$ & .003 \\
\hline \multicolumn{6}{|l|}{ Nutrition Advice (\%) } \\
\hline Physician & $73 \%$ & $54 \%$ & $61 \%$ & $46 \%$ & \\
\hline Dietitian & $13 \%$ & $14 \%$ & $10 \%$ & $18 \%$ & \\
\hline TV/Books & $8 \%$ & $23 \%$ & $22 \%$ & $24 \%$ & \\
\hline Other & $5 \%$ & $5 \%$ & $5 \%$ & $7 \%$ & \\
\hline None & $1 \%$ & $4 \%$ & $2 \%$ & $6 \%$ & .002 \\
\hline \multicolumn{6}{|l|}{ Cravings (\%) } \\
\hline Chocolate & $26 \%$ & $24 \%$ & & & \\
\hline Salty Foods & $26 \%$ & $16 \%$ & & & \\
\hline Spicy Foods & $27 \%$ & $16 \%$ & & & \\
\hline Pastries & $32 \%$ & $32 \%$ & & & \\
\hline Fruits & $24 \%$ & $33 \%$ & & & \\
\hline Ice Cream & $29 \%$ & $32 \%$ & & & \\
\hline Candy & $4 \%$ & $5 \%$ & & & \\
\hline Other & $5 \%$ & $13 \%$ & & & NS ** \\
\hline \multicolumn{6}{|l|}{ Aversions (\%) } \\
\hline Fried Foods & & $33 \%$ & & $25 \%$ & \\
\hline Cigarettes & & $40 \%$ & & $30 \%$ & \\
\hline Red Meat & & $19 \%$ & & $16 \%$ & \\
\hline Carbonated Beverages & & $7 \%$ & & $10 \%$ & \\
\hline Poultry & & $6 \%$ & & $7 \%$ & \\
\hline Tomatoes & & $11 \%$ & & $10 \%$ & \\
\hline Coffee & & $31 \%$ & & $23 \%$ & \\
\hline Alcohol & & $14 \%$ & & $18 \%$ & \\
\hline Other & & $39 \%$ & & $41 \%$ & $N S * *$ \\
\hline
\end{tabular}

Values are given as means \pm standard deviations for continuous variables and percent frequency for categorical variables. $* \mathrm{NS}$ is not significant, $\mathrm{p}$ value $>.05$, two-tailed. $* *$ with Bonferroni correction for the number of categories ( 8 for cravings, 9 for aversions) 
ton pregnancies, but have not been evaluated in terms of their effects on birthweight [3, 16-18, 31].

Maternal nutrition has gained increasing recognition in recent decades, with the liberalisation of weight gain recommendations in the 8th edition of the Food and Nutrition Board's Recommended Dietary Allowances in 1974 [12], the publication of the comprehensive report, Nutrition During Pregnancy, by the National Academy of Sciences in 1990 [13], and the publication of the American College of Obstetricians and Gynecologists' Technical Bulletin, Nutrition During Pregnancy, in 1993 [28]. Guidelines for Perinatal Care (published jointly by the American Academy of Pediatrics and the American College of Obstetricians and Gynecologists) has included prenatal nutrition since its first edition in 1983, and stresses maternal nutrition as an important component of prenatal care [2]. These guidelines recommend that each woman have a complete nutritional assessment, preferably by a nutritionist or registered dietitian [2]. As high-risk pregnancies, it is even more important that mothers pregnant with twins receive nutrition advice. In this study, $97 \%$ of women received nutrition advice, including nearly $72 \%$ from a physician or registered dietitian.

The data from this study indicate that women who receive nutrition advice from a registered dietitian were the most likely to have the best weight gains and the lowest proportion of very low birthweight infants. These differences have important clinical implications for infant morbidity, mortality, and, among survivors, subsequent childhood growth and development. Nutrition counselling has consistently been demonstrated to be cost-effective, with studies reporting cost-to-benefit ratios ranging from 1:3 to $1: 5$ [6, 29 ]. Within the field of dietetics, maternal nutrition has been cited as being a critical component of preventive prenatal care [4]. Because of their specialized training and experience, registered dietitians are more effective in making dietary assessments and prescriptions for pregnant women, as well as being more aware of pregnancy-related dietary beliefs and customs [9]. A regional survey reported that dietitians were more likely to use high-risk pregnancy screening and treatment protocols, including guidelines for weight gain, preparation of nutrition care plans, assessment of dietary and biochemical factors, health behavior, and obstetrical history [15].

Maternal weight gain was also a significant factor in both models of twin birthweight. Current maternal weight gain recommendations from the National Academy of Sciences for a twin pregnancy are $35-45$ pounds [13]. Other studies have suggested gains of 44 pounds [30], and 41-44 pounds [5], 24 pounds by 24 weeks and 40-45 pounds in $35-38$ weeks $[20,22]$. In this study, mean weight gain for birthweights $>2,500 \mathrm{~g}$ was 44.8 pounds. Mean weight gain was highest among mothers who received their nutrition advice from a registered dietitian, with $60 \%$ of these mothers gaining $\geq 40$ pounds. Studies with singleton pregnancies have shown that physicians are more likely to recommend lower weight gains, particularly to black women and women with less education $[35,36]$

Cravings and aversions during pregnancy have been reported for many years, but without any clinical implications. The foods and other substances cited in this study reflect those that had been commonly reported in earlier studies. Aversions to alcohol $[16,31]$ and cigarettes [16] may be a physiologically protective response during pregnancy. Data from the Pregnancy Nutrition Surveillance System of the Centers for Disease Control and Prevention indicates that the proportion of women who smoked or drank alcohol before versus during pregnancy decreases from $32 \%$ to $26 \%$, and from 
$14 \%$ to $4 \%$, respectively [10]. Some of this decline may be due to patient education, but some may be simply due to a natural aversion to these toxic substances during pregnancy. The most commonly cited cravings during pregnancy include fruits, sweets and chocolate, ice cream, and salty and spicy foods $[16,31]$. These foods, too, may have a physiologic basis, reflecting the higher carbohydrate and sodium needs during pregnancy, and changes in taste sensitivity [3].

These changes may be exaggerated during twin pregnancies, due to the higher levels of placentally-derived hormones [11,32], as well as the greater expansion of the plasma volume [8], and more dramatic alterations in carbohydrate metabolism [7, 34]. One of the normal responses to pregnancy is weight gain, a physiologic effect which is in part hormonally-mediated. The effect of placentally-derived hormones on weight gain has been demonstrated in the difference between monozygotic and dizygotic twin pregnancies [32]. Although it is not completely clear, cravings and aversions may also be related to the levels or fluctuations of hormones.

This study highlights the importance of maternal nutrition, especially in twin gestations because of their high risk for being premature and low birthweight. Nutrition counselling is an important component of preventive prenatal care, particularly for women pregnant with twins.

Acknowledgements: I am grateful to Virginia Seyler, Peter Wissel, Maureen Murtaugh, Catherine Brewer, Cynthia Williams, Sheila Macomber, Luis Padilla-Paz and Boris Vatel for their help in data Collection.

\section{REFERENCES}

1. Abrams BF, Laros RK (1986): Prepregnancy weight, weight gain, and birth weight. Am J Obstet Gynecol 154: 503-9.

2. American Academy of Pediatrics and the American College of Obstetricians and Gynecologists. Guidelines for Perinatal Care, 4th edition. Elk Grove, Illinois: American Academy of Pediatrics, 1997.

3. Brown JE, Toma RB (1986): Taste changes during pregnancy. Am J Clin Nutr 43: 414-8.

4. Brown JE (1989): Improving pregnancy outcomes in the United States: The importance of preventive nutrition services. J Am Dietet Assoc 89: 631-3.

5. Brown JE, Schloesser PT (1990): Prepregnancy weight status, prenatal weight gain, and the outcome of term twin gestations. Am J Obstet Gynecol 162: 182-6.

6. Buescher PA, Larson LC, Nelson MD, Lenihan AJ (1993): Prenatal WIC participation can reduce low birth weight and newborn medical costs: A cost-benefit analysis of WIC participation in North Carolina. J Am Dietet Assoc 93: 163-6.

7. Campbell DM, MacGillivray I (1979): Glucose tolerance in twin pregnancy. Acta Genet Med Gemellol 28: 283-7.

8. Campbell DM, MacGillivray I (1984): The importance of plasma volume expansion and nutrition in twin pregnancy. Acta Genet Med Gemellol: 33: 19-24.

9. Carruth BR, Skinner JD (1991): Practitioners beware: Regional differences in beliefs about nutrition during pregnancy. J Am Dietet Assoc 91: 435-40.

10. Centers for Disease Control and Prevention. Pregnancy Nutrition Surveillance System-United States, 1979-1990. CDC Surveillance Summaries, November 27, 1992. Morbidity and Mortality Weekly Report 1992; 41 (No. SS-7): 25-41. 
11. Duff GB, Brown JB (1974): Urinary oestriol excretion in twin pregnancies. J Obstet Gynaecol Brit Commwlth 81: 695-700.

12. Food and Nutrition Board. Recommended Dietary Allowances, 8th edition. Washington, DC: National Academy Press, 1974.

13. Food and Nutrition Board. Nutrition During Pregnancy. Washington, DC: National Academy Press, 1990.

14. Gormican A, Valentine J, Satter E (1980): Relationships of maternal weight gain, prepregnancy weight, and infant birthweight. J Am Dietet Assoc 77: 662-7.

15. Haughton B, Costello C, Traylor MN, Reeves K (1992): Public health nutrition practices to prevent low birth weight in eight southeastern states. J Am Dietet Assoc 92: 187-91.

16. Hook EB (1978): Dietary cravings and aversions during pregnancy. Am J Clin Nutr 31:135562.

17. Hook EB (1980): Influence of pregnancy on dietary selection. Intern J Obesity 4: 338-40.

18. Horner RD, Lackey CJ, Kolasa K, Warren K (1991): Pica practices of pregnant women. J Am Dietet Assoc 91: 34-8.

19. Luke B, Keith LG (1992): The contribution of singletons, twins, and triplets to low birthweight, infant mortality, and handicap in the United States. J Reprod Med 37: 661-6.

20. Luke B, Minogue J, Abbey H, Keith L, Witter FR, Feng TI, Johnson TRB (1992): The association between maternal weight gain and the birthweight of twins. J Maternal-Fetal Med 1: 267-76.

21. Luke B, Minogue J, Witter FR (1993): The role of fetal growth restriction and gestational age on length of hospital stay in twin infants. Obstet Gynecol 81: 949-53.

22. Luke B, Minogue J, Witter FR, Keith LG, Johnson TRB (1993): The ideal twin pregnancy: Patterns of weight gain, discordancy, and length of gestation. Am J Obstet Gynecol 169: 588-97.

23. Luke B (1994): The changing pattern of multiple births in the United States: Maternal and infant characteristics, 1973 and 1990. Obstet Gynecol 84: 101-6.

24. Luke B, Minogue J (1994): Contribution of gestational age and birth weight to perinatal viability in singletons vs twins. J Maternal-Fetal Med 3: 263-74.

25. Luke B, Leurgans S (1996): Maternal weight gains in ideal twin outcomes. J Am Dietet Assoc 96: $178-81$.

26. Luke B, Gillespie B, Min S-J, Avni M, Witter FR, O'Sullivan MJ (1997): Critical periods of maternal weight gain: Effect on twin birthweight. Am J Obstet Gynecol 177: 1055-62.

27. Mitchell MC, Lerner E (1989): Weight gain and pregnancy outcome in underweight and normal weight women. J Am Dietet Assoc 89: 634-8.

28. Nutrition During Pregnancy. Technical Bulletin No. 179. Washington, DC: American College of Obstetricians and Gynecologists, 1993.

29. Orstead C, Arrington D, Kamath SK, Olson R, Kohrs MB (1985): Efficacy of prenatal nutrition counselling: Weight gain, infant birth weight, and cost-effectiveness. J Am Dietet Assoc 85: 40-5.

30. Pederson AL, Worthington-Roberts B. Hickok DE (1989): Weight gain patterns during twin gestation. J Am Dietet Assoc 89: 642-6.

31. Pope JF, Skinner JD, Carruth BR (1992): Cravings and aversions of pregnant adolescents. J Am Dietet Assoc 92: 1479-82.

32. Schneider L, Rigaud M, Tabaste J-L, Chebroux P, Lacour B, Baudet J (1978): HPL measurements: Relationships with maternal weight gain in twin pregnancy, in Allen G. Nance WE, Parisi P (eds). Twin Research: Clinical Studies. New York: Alan R. Liss, pp. 123-8.

33. Seidman DS, Ever-Hadani P, Gale R (1989): The effect of maternal weight gain in pregnancy on birth weight. Obstet Gynecol 74: 240-6.

34. Spellacy WN, Buhi WC, Birk SA (1980): Carbohydrate metabolism in women with a twin pregnancy. Obstet Gynecol 688-91.

35. Taffel SM, Keppel KG (1986): Advice about weight gain during pregnancy and actual weight gain. Am J Public Health 76: 1396-9. 


\section{B. Luke et al.}

36. Taffel SM, Keppel KG, Jones GK (1993): Medical advice on maternal weight gain and actual weight gain: Results from the 1988 National Maternal and Infant Health Survey, in Keen CL, Bendich A, Willhite CC (eds) Maternal Nutrition and Pregnancy Outcome. Ann NY Acad Sci 678: 293-305.

37. Ventura SJ, Martin JA, Curtin SC, Mathews TJ: Report of final natality statistics, 1995. Monthly Vital Statistics Report, vol. 45, no. 11, supplement. Hyattsville, MD: National Center for Health Statistics, 1997.

38. Winikoff B, Debrovner CH (1981): Anthropometric determinants of birth weight. Obstet Gynecol 58: 678-84.

39. Worthington-Roberts B, Little RE, Lambert MD, Wu R (1989): Dietary cravings and aversions in the postpartum period. J Am Dietet Assoc 89: 647-51.

Correspondence: Barbara Luke, ScD, MPH, RD, Dept. Obstetrics and Gynecology, University of Michigan Medical School, F4866 Mott, 1500 East Medical Center Drive, Ann Arbor, Michigan 481090264, USA. 